\title{
Cocaine-Induced Synaptic Alterations in Thalamus to Nucleus Accumbens Projection
}

\author{
Peter A Neumann', Yicun Wang' ${ }^{2}$ Yijin Yan $^{3}$, Yao Wang ${ }^{3}$, Masago Ishikawa', Ranji Cui ${ }^{2}$, Yanhua H Huang ${ }^{3}$, \\ Susan R Sesack ${ }^{1,3}$, Oliver M Schlüter' and Yan Dong ${ }^{*, 1,3}$ \\ 'Department of Neuroscience, University of Pittsburgh, Pittsburgh, PA, USA; ${ }^{2}$ The Second Hospital of jilin University, Changchun, jilin, China; \\ ${ }^{3}$ Department of Psychiatry, University of Pittsburgh, Pittsburgh, PA, USA
}

\begin{abstract}
Exposure to cocaine induces addiction-associated behaviors partially through remodeling neurocircuits in the nucleus accumbens (NAc). The paraventricular nucleus of thalamus (PVT), which projects to the NAc monosynaptically, is activated by cocaine exposure and has been implicated in several cocaine-induced emotional and motivational states. Here we show that disrupting synaptic transmission of select PVT neurons with tetanus toxin activated via retrograde trans-synaptic transport of cre from NAc efferents decreased cocaine selfadministration in rats. This projection underwent complex adaptations after self-administration of cocaine $(0.75 \mathrm{mg} / \mathrm{kg} / \mathrm{infusion} ; 2 \mathrm{~h} / \mathrm{d} \times 5 \mathrm{~d}$, I d overnight training). Specifically, Id after cocaine self-administration, we observed increased levels of AMPA receptor (AMPAR)-silent glutamatergic synapses in this projection, accompanied by a decreased ratio of AMPAR-to-NMDA receptor (NMDAR)-mediated EPSCs. Furthermore, the decay kinetics of NMDAR EPSCs was significantly prolonged, suggesting insertion of new GluN2B-containing NMDARs to PVT-to-NAc synapses. After 45-d withdrawal, silent synapses within this projection returned to the basal levels, accompanied by a return of the AMPAR/NMDAR ratio and NMDAR decay kinetics to the basal levels. In amygdala and infralimbic prefrontal cortical projections to the NAc, a portion of cocaine-generated silent synapses becomes unsilenced by recruiting calcium-permeable AMPARs (CP-AMPARs) after drug withdrawal. However, the sensitivity of PVT-to-NAc synapses to CP-AMPAR-selective antagonists was not changed after withdrawal, suggesting that CP-AMPAR trafficking is not involved in the evolution of cocaine-generated silent synapses within this projection. Meanwhile, the release probability of PVT-to-NAc synapses was increased after short- and long-term cocaine withdrawal. These results reveal complex and profound alterations at PVT-to-NAc synapses after cocaine exposure and withdrawal.

Neuropsychopharmacology (2016) 4I, 2399-24I0; doi: 10.1038/npp.20I6.52; published online 4 May 2016
\end{abstract}

\section{INTRODUCTION}

Excitatory synaptic projections to the nucleus accumbens (NAc) are key neural targets for cocaine experience and can be reshaped to alter NAc-based emotions and motivations (Wolf, 2010). The NAc receives extensive excitatory projections from the limbic and paralimbic regions. One of the less-examined major projections is from the paraventricular nucleus of the thalamus (PVT), which, as a subnucleus of the thalamus, lies on the midline just ventral to the third ventricle (Van der Werf et al, 2002; Smith et al, 2004). The PVT projection often converges with other excitatory inputs or midbrain-originated dopaminergic terminals onto the same NAc medium spiny neurons (MSNs; Berendse and Groenewegen, 1990; O'Donnell et al, 1997; Otake and Nakamura, 1998; Pinto et al, 2003; Vertes and Hoover, 2008). This anatomical setup allows the PVT-to-NAc projection to either activate NAc MSNs directly or interact

\footnotetext{
*Correspondence: Dr Y Dong, Department of Neuroscience, University of Pittsburgh, A210 Langley Hall/5th and Ruskin Avenue, Pittsburgh, PA 15260, USA, Tel: + I 4I26243|40, Fax: + I 412624 9198, E-mail: yandong@pitt.edu

Received 25 August 2015; revised 9 March 2016; accepted 30 March 2016; accepted article preview online 14 April 2016
}

with other inputs. Whereas the role of the PVT in cocaine- or cue-induced drug responses has been explored in several studies (Brown et al, 1992; James et al, 2010; Browning et al, 2014; Matzeu et al, 2014), it remains elusive whether the PVT-to-NAc projection is required for cocaine-induced behaviors and whether this projection is subject to cocaineinduced remodeling.

After cocaine self-administration, profound adaptive changes have been identified at NAc synapses. Presynaptically, an increased release probability is observed at prefrontal cortex to NAc synapses after short- and longterm cocaine withdrawal (Suska et al, 2013). Postsynaptically, a large number of calcium-permeable (CP) AMPA receptors (AMPARs) accumulate at excitatory synapses after long-term withdrawal from cocaine self-administration (Conrad et al, 2008). Structurally, the density of dendritic spines, the postsynaptic structures of excitatory synapses, is increased after cocaine withdrawal (Robinson and Kolb, 2004). The new spines are thought to be nascent synapses, generated initially as AMPAR-silent synapses after cocaine exposure and mature into AMPAR-present synapses after cocaine withdrawal to remodel the NAc circuits (Huang et al, 2009; Lee and Dong, 2011; Huang et al, 2013; Dong and Nestler, 2014). This notion has been further examined in two 
limbic projections to the NAc shell, the prefrontal cortical and amygdala projections, in which silent synapses are generated after cocaine self-administration, and a portion of them unsilences to become fully functional synapses by recruiting CP-AMPARs (Lee et al, 2013; Ma et al, 2014).

To characterize cocaine-induced adaptations at PVT-toNAc synapses, we used viral tools to selectively manipulate PVT neurons projecting to the NAc in rats. Briefly, this manipulation involves viral expression of flexed (Creinducible inversion) tetanus toxin in PVT neurons and viral expression of cre in NAc shell neurons, which is fused with wheat germ agglutinin (WGA) so it is retrogradely transsynaptically transported, such that tetanus toxin is only activated and expressed in infected PVT neurons that project to infected NAc neurons. This technique has been extensively characterized (Braz et al, 2002; Auer et al, 2010; Xu and Sudhof, 2013; Christoffel et al, 2015) and has been reliably used to block synaptic transmission within the PVTto-NAc pathway (Christoffel et al, 2015). Our results show that disrupting synaptic transmission of PVT neurons that project to the NAc shell substantially decreased the acquisition of cocaine self-administration $(0.75 \mathrm{mg} / \mathrm{kg} / \mathrm{infu}-$ sion; $2 \mathrm{~h} / \mathrm{d} \times 5 \mathrm{~d}$ after 1 overnight training). Furthermore, cocaine self-administration generated silent synapses in the PVT-to-NAc projection, and the subsequent evolution of these silent synapses did not involve CP-AMPAR trafficking. Moreover, the release probability of PVT-to-NAc synapses was persistently increased after cocaine withdrawal. These results reveal complex cocaine-induced adaptations at PVTto-NAc synapses.

\section{MATERIALS AND METHODS}

\section{Subjects}

The subjects were male Sprague-Dawley rats (Charles River, PA) aged 30-40 days before surgery. Rats were housed on a regular 12-h light/dark cycle (light on at 0700 hours) with food and water ad libitum. Before surgical procedures, rats were allowed to acclimate to their home cages for $>4 \mathrm{~d}$.

\section{Virus Preparation}

Channelrhodopsin-2 (ChR2, H134R variant) fused to Venus (Addgene plasmid 20071) was under the control of a CAG promoter in an adeno-associated viral vector (AAV) with AAV2 ITRs: AAV-ChR2Y (Mattis et al, 2012). AAV1/2 serotype AAV vectors were generated as described previously (Klugmann et al, 2005; Pilpel et al, 2009). Briefly, human embryonic kidney 293T cells were transfected with the AAVChR2 plasmid, AAV1 (pH21) and AAV2 (pRV1) helper plasmids, and the adenovirus helper plasmid $(\mathrm{pF} \Delta 6)$ by standard polyethylenimine transfection. Cells were harvested 48-72 $\mathrm{h}$ after transfection and purified by discontinuous iodixanol gradient centrifugation. After desalting by Amicon 100k concentrators (Millipore) with PBS-MK, AAV vectors were stored at $-80^{\circ} \mathrm{C}$ until further use.

For the WGA-cre AAV vector, the following components were arranged sequentially downstream of left-ITR of AAV2: synapsin promoter, mCherry, IRES, WGA-cre fusion, WPRE, hGH poly A sequence, and right ITR. For the DoubleFloxInverted-TetTox AAV vector (DIO-TetTox), the following components were arranged sequentially downstream of left-ITR of AAV2: CMV promoter and beta-globin intron, loxp2272, loxp, inverted EGFP-2A-TetTox, loxp2272, loxp, hGH poly A sequence, and right ITR. AAVs were packaged with AAV-DJ capsids for high-efficiency in vivo neuronal infection. Virus was prepared with a procedure as described previously (Zolotukhin et al, 1999). Briefly, AAV vectors were co-transfected with pHelper and pRC-DJ into AAV-293 cells. Seventy-two hours later, cells were collected, lysed, and loaded onto iodixanol gradient for centrifugation at $400000 \mathrm{~g}$ for $2 \mathrm{~h}$. The fraction with $40 \%$ iodixanol of the gradient was collected, washed, and concentrated with 100000 MWCO tube filter. The infectious titer of the virus was measured by infecting HEK293 cells.

\section{Intravenous Surgery and In Vivo Virus Delivery}

To infect NAc shell MSNs and PVT neurons in vivo, a stereotaxic microinjection was performed. Rats were anesthetized with a xylazine-ketamine mixture (5-10/ $50-100 \mathrm{mg} / \mathrm{kg}$, i.p.). A stainless steel cannula was lowered bilaterally into the NAc shell (in mm: A, 1.5; L, 0.8; D, -7.2) or unilaterally down the midline into the PVT $(\mathrm{A},-2.7$; $\mathrm{L}$, $0.0 ; \mathrm{D}-5.3)$. Concentrated viral solutions $(1 \mu \mathrm{l} /$ site $)$ were injected into the NAc shell and PVT through a pump at a flow rate of $0.2 \mu \mathrm{l} / \mathrm{min}$. Cannulas were left in place for $5 \mathrm{~min}$ after infusions were complete before being slowly withdrawn. Although still under anesthesia, a catheter was inserted into the jugular vein and passed subcutaneously to the midscapular where it exited and connected to a harness with quick connect luer (SAI) (Mu et al, 2010). Rats were then placed on a warmed heating pad for postsurgical recovery. Upon waking up, rats were transferred to regular housing cages and given 7-14 $\mathrm{d}$ to recover before beginning self-administration training sessions. Catheters were flushed with sterile saline containing gentamicin $(5 \mathrm{mg} / \mathrm{ml})$ and heparin (10 UPS/ml) every $24 \mathrm{~h}$ during recovery and training.

\section{Self-Administration Training and Apparatus}

Seven-to-14 days after surgery, rats underwent a single overnight training session in a self-administration operant chamber before beginning a series of $5-\mathrm{d} 2 \mathrm{~h} / \mathrm{d}$ selfadministration sessions. Self-administration chambers, controlled by a Med Associates (Georgia, VT) system, had two nose poke holes located $6 \mathrm{~cm}$ above the grid floor, but only one hole (active hole) activated the infusion pump. The luer on the harness was connected to a liquid swivel with dual-luer spring tether and connected to the syringe of the infusion pump. Nose pokes in the other (inactive) hole were also recorded. A nose poke to the active hole resulted in a cocaine infusion, accompanied by the switch-on of a light as a conditioned stimulus (CS) and a background light. The CS stayed on for $6 \mathrm{~s}$, and the background light for $20 \mathrm{~s}$. During this $20 \mathrm{~s}$, additional nose pokes were counted but did not result in cocaine infusion. After completion of 5-d self-administration training ( $>15$ infusions $/ 2 \mathrm{~h}$ session/d at $0.75 \mathrm{mg} / \mathrm{kg} /$ infusion for cocaine groups), animals were placed into their home cages for withdrawal. For sucrose self-administration, $\sim 20$ days after viral injections, we trained rats to self-administer (nosepoke) sucrose pellets (45 mg) 
under the same experimental conditions (session duration and reinforcement schedule) we used in the cocaine self-administration studies. The rats were food restricted in their home cage with the body weight maintained 95\% of their original values.

\section{Preparation of NAc Slices}

The detailed procedure for obtaining NAc slices is described previously (Dong et al, 2006; Huang et al, 2008). Briefly, rats (aged $\sim 50-60 \mathrm{~d}$ for short-term withdrawal experiments and $\sim 100 \mathrm{~d}$ for long-term experiments) were deeply anesthetized with isofluorane and decapitated. Acute coronal NAc and PVT slices $(250 \mu \mathrm{m}$ thick) were obtained (normally $3 \mathrm{NAc}$ and 4-6 PVT slices were obtained from each rat) using a VT1200S vibratome (Leica, Germany) in $4{ }^{\circ} \mathrm{C}$ cutting solution containing (in $\mathrm{mM}$ ): $135 \mathrm{~N}$-methyl-D-glucamine, $1 \mathrm{KCl}$, $1.2 \mathrm{KH}_{2} \mathrm{PO}_{4}, 0.5 \mathrm{CaCl}_{2}, 1.5 \mathrm{MgCl}_{2}, 20$ choline- $\mathrm{HCO}_{3}$, and 11 glucose, saturated with $95 \% \mathrm{O}_{2} / 5 \% \mathrm{CO}_{2}$, $\mathrm{pH}$ adjusted to 7.4 with $\mathrm{HCl}$. Slices were incubated in artificial cerebrospinal fluid (aCSF) containing (in mM): $119 \mathrm{NaCl}, 2.5 \mathrm{KCl}, 2.5$ $\mathrm{CaCl}_{2}, 1.3 \mathrm{MgCl}_{2}, 1 \mathrm{NaH}_{2} \mathrm{PO}_{4}, 26.2 \mathrm{NaHCO}_{3}$, and 11 glucose, saturated with $95 \% \mathrm{O}_{2} / 5 \% \mathrm{CO}_{2}$ at $37^{\circ} \mathrm{C}$ for $30 \mathrm{~min}$ and then allowed to recover for $>30 \mathrm{~min}$ at room temperature before experimentation.

\section{Electrophysiological Recordings}

All recordings were made from MSNs located in the NAc shell. During recordings, slices were superfused with aCSF that was heated to $31-33^{\circ} \mathrm{C}$ by passing the solution through a feedback-controlled in-line heater (Warner, CT) before entering the chamber. To record AMPAR and/or NMDAR EPSCs, electrodes (2-5 M $\Omega$ ) were filled with (in $\mathrm{mM}$ ): 140 $\mathrm{CsCH}_{3} \mathrm{O}_{3} \mathrm{~S}$, 5 TEA-Cl, 0.4 Cs-EGTA, 20 Hepes, $2.5 \mathrm{Mg}$-ATP, $0.25 \mathrm{Na}-\mathrm{GTP}$, and $1 \mathrm{QX}-314, \mathrm{pH}$ 7.3. Presynaptic afferents were stimulated using blue light $(473 \mathrm{~nm})$ DPSS laser (IkeCool) coupled to a $62.5-\mu \mathrm{m}$ optic fiber, generated using the Clampex software (Molecular Devices). Collimated laser light was coupled to a fluorescent port of the Olympus BX51WI microscope, allowing the blue laser light to illuminate the slice through the objective, focused on the cell. Optical stimulations of $1.0-0.1-\mathrm{ms}$ duration were used to stimulate at $0.1 \mathrm{~Hz}$ for paired-pulse or AMPAR/NMDAR ratio measurements, $0.04 \mathrm{~Hz}$ for trains of 5 pulses $(50 \mathrm{~ms}$ inter-pulse interval), and $0.17 \mathrm{~Hz}$ for minimal stimulation measurements. Series resistance was 9-20 M $\Omega$, uncompensated, and monitored continuously during recording. Cells with a change in series resistance beyond $20 \%$ were not accepted for data analysis. Synaptic currents were recorded with a MultiClamp $700 \mathrm{~B}$ amplifier, filtered at $2.6-3 \mathrm{kHz}$, amplified 5 times, and then digitized at $20 \mathrm{kHz}$. Picrotoxin $(100 \mu \mathrm{M})$ was included to inhibit $\mathrm{GABA}_{\mathrm{A}}$ receptor-mediated currents in all experiments. Local application of Naspm $(150 \mu \mathrm{M})$ was used to block CP-AMPAR-mediated currents in some experiments.

\section{Staining, Fluorescence, and Imaging}

Biotinylated dextran amine (BDA; 10000 molecular weight, Molecular Probes, dissolved as a $10 \%$ solution in $10 \mathrm{mM}$ sodium phosphate buffer) was injected into the PVT at
$2.4 \mathrm{~mm}$ posterior to Bregma, $1.1 \mathrm{~mm}$ lateral to the midline, and $5.45 \mathrm{~mm}$ ventral to the skull surface by using a $14^{\circ}$ angle relative to the midline vertical axis. The tracer was delivered by iontophoresis through a glass pipette with $50-75-\mu \mathrm{m}$ tip diameter using a positive $5-\mu \mathrm{A}$ current pulsed $10 \mathrm{~s}$ on and off for a total of $30 \mathrm{~min}$. The pipette was then left in place for an additional $5 \mathrm{~min}$. After 5 -d recovery, the animals were deeply anesthetized with sodium pentobarbital $(100 \mathrm{mg} / \mathrm{kg}$, i.p.). Tissues from these rat brains were used for multiple purposes. One of these purposes required the chelation of endogenous zinc. Consequently, animals receiving BDA injections were subsequently treated for $15 \mathrm{~min}$ with $1 \mathrm{~g} / \mathrm{kg}$, i.p. of a zinc chelator, diethyldithiocarbamic acid (Sigma) (Veznedaroglu and Milner, 1992). All rats were perfused through the aorta with $10 \mathrm{ml}$ of a heparin-saline solution ( $1000 \mathrm{U} / \mathrm{ml}$ heparin in $0.9 \%$ saline) followed by $50 \mathrm{ml}$ of $3.75 \%$ acrolein in $2 \%$ paraformaldehyde and finally $250 \mathrm{ml}$ of $2 \%$ paraformaldehyde in $0.1 \mathrm{M}$ phosphate buffer $(\mathrm{PB}), \mathrm{pH}$ 7.4. The brains were extracted, postfixed in $2 \%$ paraformaldehyde for $1 \mathrm{~h}$, and sectioned at approximately $50 \mu \mathrm{m}$ by using a vibratome. Sections were then mounted on glass slides, dehydrated, and cover-slipped. Pictures were taken on an Olympus BM51 microscope.

For imaging WGA-cre and DIO-TetToxAAV-mediated fluorescence, 3-7 d following behavioral testing, animals were perfused with $50 \mathrm{ml}$ PBS and $150 \mathrm{ml}$ of $4 \%$ PFA. Brains were then extracted and postfixed in 4\% PFA overnight. The following day, brains were transferred to $15 \%$ sucrose $0.1 \mathrm{M}$ $\mathrm{PB}$ solution for an additional day before being transferred to $30 \%$ sucrose $0.1 \mathrm{M} \mathrm{PB}$ solution. Two-to-7 d later, brains were sliced into $40-\mu \mathrm{m}$ coronal sections, and slices containing the NAc or PVT were mounted onto glass slides using a mixture of PBS and mounting gel, containing water $(500 \mathrm{ml})$, gelatin $(2.5 \mathrm{~g})$, and chromium potassium sulfate $(0.25 \mathrm{~g})$, and dehydrated. Pictures were taken on an Olympus BM51 microscope.

\section{Drugs}

All chemicals were purchased from Sigma-Aldrich. Cocaine$\mathrm{HCl}$ was supplied by the Drug Supply Program of the National Institute on Drug Abuse.

\section{Data Acquisition and Statistics}

All data were analyzed offline. Statistical results are expressed as mean \pm SEM. Two-tailed $t$-test or ANOVA was used for statistical comparisons as specified in the text.

NMDAR currents were elicited at a $+50 \mathrm{mV}$ holding potential. NMDAR amplitude was operationally defined as the amplitude of the current $40 \mathrm{~ms}$ after the onset of the evoked current; at this time point, AMPAR-mediated currents have subsided. For experiments involving Naspm application, averaged evoked EPSC amplitudes during the initial 1-5 min baseline period were compared with average evoked EPSC amplitudes following application of Naspm (11-16 min) using paired $t$-test. For comparisons between groups, EPSC amplitudes of each cell were averaged and normalized to the initial 5-min baseline period and then compared using independent $t$-test.

For variance-mean analysis (multiple probability fluctuation analysis (MPFA)), 30-100 AMPAR EPSCs were used 
from each cell at five release probability conditions achieved by a five-pulse train of presynaptic stimulations with a 50-ms interpulse interval (Scheuss and Neher, 2001; Silver, 2003). The peak amplitude of each EPSC was compared with its baseline and averaged to measure the mean EPSC response amplitude (I). Variance of each EPSC peak was calculated and plotted against their mean amplitude. We assume that presynaptic release sites operate independently and that the release probability of synapses is the same. Thus the amplitudes of EPSCs can be expressed as:

$I=N \operatorname{Pr} Q$

where $N$ is the number of release sites, $\operatorname{Pr}$ is the presynaptic release probability, and $Q$ is the quantal size (amplitude of EPSC from release of one quantum). For a binomial model, the variance $\left(\sigma^{2}\right)$ of EPSC amplitudes can be expressed as:

$\sigma^{2}=N Q^{2} \operatorname{Pr}(1-\operatorname{Pr})$

Based on the two above equations, the following equation can be derived:

$\sigma^{2}=I Q-(I / N)^{2}$

This equation predicts a parabolic relationship between $\sigma^{2}$ and $I$. As such, the variance-mean relationship was fit with equation (3) to estimate $N$ and $Q$ in each examined cell. $\operatorname{Pr}$ was then calculated with equation (1). If any of the theoretical assumptions do not hold true (eg, if multivesicular release exists), the points along the $\sigma^{2}-I$ curve would not exhibit a well-fitting parabolic relationship. Twenty-two cells among the total of 70 recorded cells undergoing $20-\mathrm{Hz}$ stimulation were not included in the final data analysis because they could not be well fitted by this relationship $\left(r^{2}<0.9\right)$ or they had minimal variance in EPSCs. In a few cells $(n=3)$, only the first four EPSCs were included in the analysis because the fifth EPSC was predominated by failed responses. $t$-Test was used to compare averaged data points between groups, and paired $t$-test was used for before-after comparisons within subjects.

\section{RESULTS}

\section{Synaptic Transmission in PVT Neurons that Project to NAc}

To verify the monosynaptic projection from the PVT to the NAc shell, we injected an anterograde dye BDA into the PVT of anesthetized rats. Five days later, we verified the accuracy of the injection site in coronal slices (Figure 1a) and observed extensive BDA-labeled neural fibers in the NAc shell (Figure 1b).

In an attempt to determine the role of PVT-to-NAc projection in acquisition of cocaine self-administration, we adopted a trans-synaptic manipulation (Xu and Sudhof, 2013), whereby we injected AAV that expresses WGA-cre and mCherry into the NAc shell and another AAV expressing EGFP and flexed tetanus toxin (Flx-TetTox) into the PVT. The TetTox and EGFP was only expressed when triggered by cre-recombinase, which was delivered by trans-synaptically transported WGA-cre (Xu and Sudhof, 2013). Thus only PVT neurons that projected to the NAc shell expressed TetTox, which in turn disrupted the synaptic release of these neurons. This technique has been characterized (Braz et al, 2002; Auer et al, 2010; Xu and Sudhof, 2013; Christoffel et al, 2015) and has been used to block synaptic transmission within the PVTto-NAc pathway (Christoffel et al, 2015). Four weeks after intra-NAc injection of WGA-cre AAVs and intra-PVT injection of Flx-TetTox AAV, a substantial number of EGFP-expressing neurons were detected in the PVT, indicating expression of TetTox within these neurons (Figure 1c). Expression of WGA-cre, as indicated by mCherry fluorescence, was also detected in the NAc in these animals (Figure 1d). In control (vehicle) rats, intra-PVT injection of the Flx-TetTox-expressing AAV was combined with intraNAc shell injection of YFP-expressing AAV (without the WGA-cre component), which did not result in the expression of EGFP and TetTox in the PVT despite apparent YFP expression in the NAc (Figure 1e-i).

To verify the functional efficacy of this viral strategy, we made paired recordings from presynaptic, TetTox-expressing

Figure I Disrupting synaptic transmission in PVT neurons that project to the NAc shell decreases cocaine self-administration. (a) Diagram (left) and image (right) showing BDA tracer injection to the PVT. (b) Diagram (left) and image (shell) showing the NAc shell containing neural fibers arising from BDA-traced PVT neurons. The square region, shown at higher magnification in the insert, illustrates axon varicosities. Scale bar in panel a represents $250 \mu \mathrm{m}$ for panels a and $b$, and $25 \mu \mathrm{m}$ for inset. (c) Image of an example coronal slice showing EGFP-TetTox expression in PVT neurons after intra-PVT injection of Flx-TetToxexpressing AAV and intra-NAc shell injection of WGA-cre-expressing AAV. Scale bar, left $500 \mu \mathrm{m}$, right I50 $\mu \mathrm{m}$. (d) Example of image showing mCherry fluorescence indicating the expression of WGA-cre in the NAc shell. Scale bar $500 \mu \mathrm{m}$. (e) Example of image showing lack of EGFP-TetTox expression in the PVT after intra-PVT injection of Flx-TetTox-expressing AAV and intra-NAc shell injection of control (without WGA-cre component) YFP-expressing AAV. Scale bar, left $500 \mu \mathrm{m}$, right I $50 \mu \mathrm{m}$. (f) Example of image showing the expression of YFP after intra-NAc shell injection of YFP-expressing control AAV vehicle (without WGA-cre). Scale bar $500 \mu \mathrm{m}$. (g) Diagram showing the injection sites (green dots) of Flx-TetTox-expressing AAV in rats for self-administration tests. (h) Diagram showing the injection sites of WGA-cre AAVs (red) and YFP AAV vehicle controls (yellow) in the NAc. (i) Experimental timeline showing when rats received stereotaxic injections of ChR2- and TetTox-expressing AAVs and underwent self-administration training. (j) Example of postsynaptic responses evoked from an uninfected, control presynaptic neuron (left) and from a presynaptic neuron expressing TetTox (right) in hippocampal cultures. (k) Upper: Example of optogenetically evoked traces in a control NAc MSN from a rat with intra-PVT expression of ChR2 alone; lower: Example of optogenetically evoked traces in a WGA-cre-expressing NAc MSN from a rat with intra-PVT expression of ChR2 and Flx-TetTox together. The black trace is the average of individual traces in each condition. (I) Rats with intra-PVT injection of TetToxAAV and intra-NAc injection of WGA-cre AAV exhibited normal sucrose selfadministration. (m) Rats with intra-PVT injections of Flx-TetTox AAV and intra-NAc injections of WGA-cre AAV also had equivalent inactive nose poke behavior. (n) After an overnight session of cocaine/saline self-administration training (left), cocaine-exposed rats exhibited equally low levels of nosepokes to inactive holes during subsequent $2 \mathrm{~h} / \mathrm{d} \times 5 \mathrm{~d}$ training (right). (o) Rats with intra-PVT injection of Flx-TetTox-expressing AAV and intra-NAc injection of WGAcre AAV exhibited decreased cocaine self-administration compared with the control and vehicle groups. (p) Summary showing that, after prolonged withdrawal from cocaine self-administration, rats with intra-PVT injection of Flx-TetTox-expressing AAV and intra-NAc injection of WGA-cre AAV exhibited similar incubation of cue-induced cocaine craving as rats without TetTox-cre manipulation. $n$ values labeled in key and bars. $* p<0.01$. 
neurons, and postsynaptic neurons in primary hippocampal cultures. IPSCs were completely blocked in all six recorded neurons receiving TetTox-expressing projections (Figure $1 \mathrm{j}$ ). Furthermore, we injected a mixture of Flx-TetTox AAV and
ChR2 AAV into the PVT and WGA-cre AAV into the NAc in rats. Three-to-4 weeks later, we obtained brain slices from these rats and made recordings from WGA-cre-expressing NAc MSNs. Optogenetic stimulation failed to elicit synaptic a
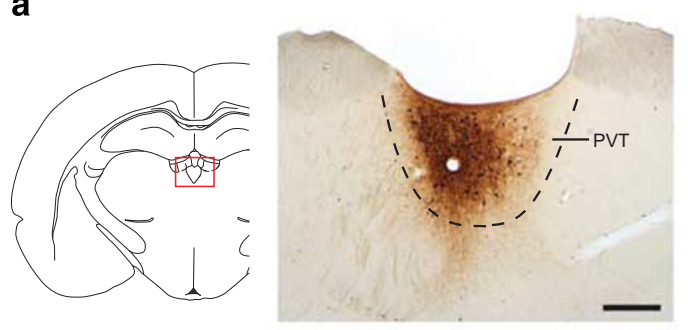

C

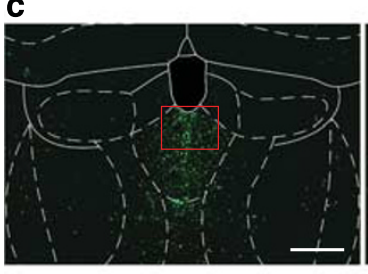

e

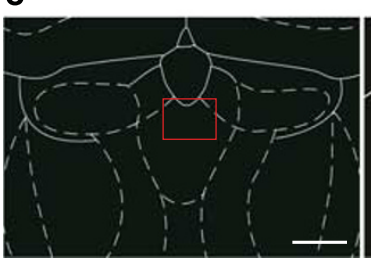

i

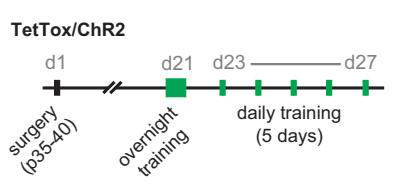

j

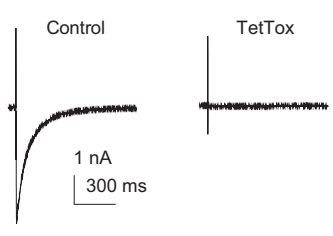

n

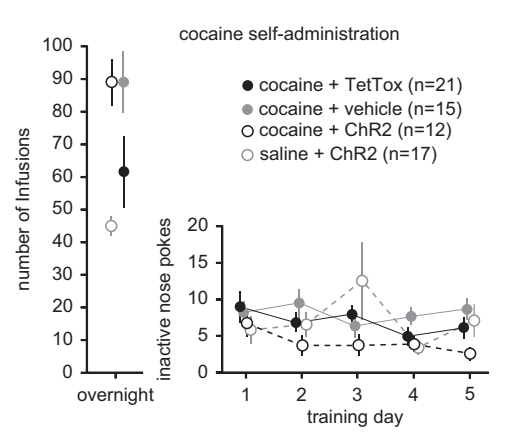

k b

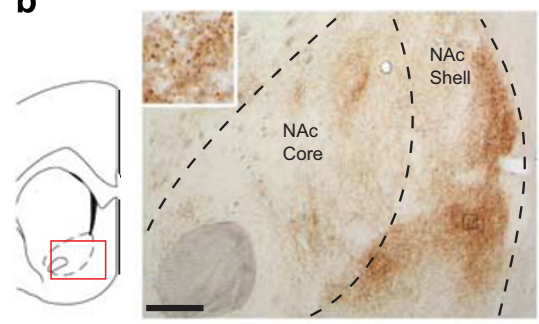

d

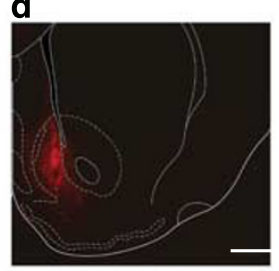

g

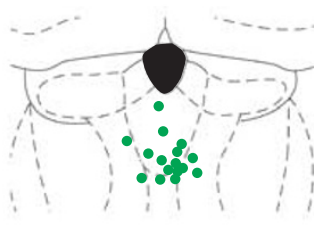

h
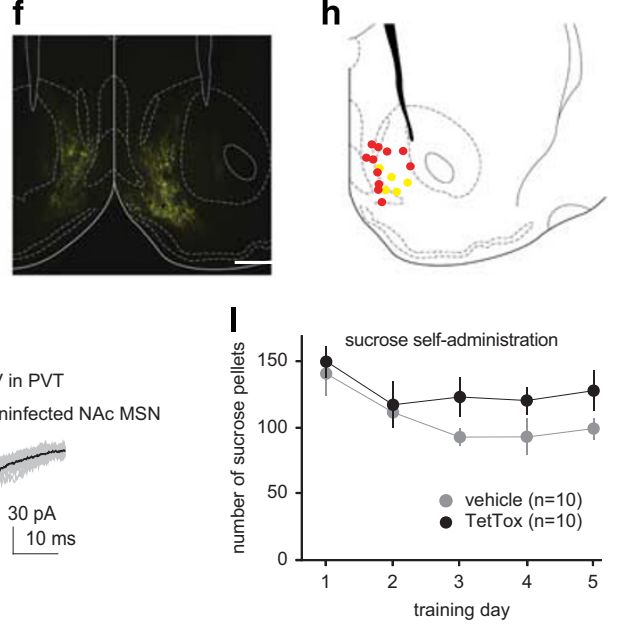

m

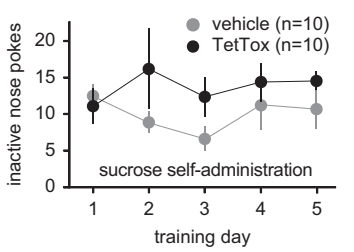

p

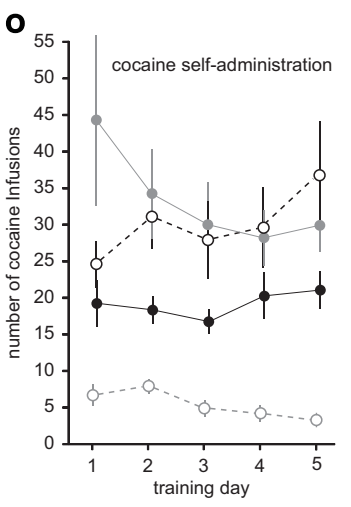

Flx-TetTox AAV + ChR2 AAV in PVT recorded from WGA-cre AAV infected NAc MSN

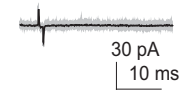


responses in all nine neurons from three rats (Figure 1k). In contrast, optogenetic stimulation routinely evoked synaptic transmission in uninfected NAc MSNs in rats receiving intra-PVT injection of ChR2 AAV alone (Figures $1 \mathrm{k}, 2$ and 3). These results suggest that expression of TetTox effectively abolishes synaptic transmission.

We then used this double-virus strategy to examine the behavioral roles of the PVT-to-NAc projection (Figure 1i). When compared with either these sham control rats or rats without viral injections, rats with intra-PVT injection of Flx-TetTox AAV and intra-NAc injection of WGA-cre AAV (injection sites verified, Figure $1 \mathrm{~g}$ and $\mathrm{h}$ ) exhibited normal sucrose self-administration (Figure $11 ; \mathrm{F}_{1,18}=2.00, p=0.17$, two-way repeated-measure ANOVA) and inactive nose poke behavior (Figure $1 \mathrm{~m} ; \mathrm{F}_{1,18}=0.004, p=0.95$, two-way repeated-measure ANOVA). We then tested a different group of rats with cocaine self-administration. After overnight training (Figure $1 \mathrm{n}$ ), rats underwent 5 -d saline or cocaine self-administration. Nose pokes to the inactive hole did not differ between control rats and rats with intra-PVT injection of Flx-TetTox AAV and intra-NAc injection of WGA-cre AAV after saline or cocaine self-administration (Figure 1n; treatment group effect: $\mathrm{F}_{3,61}=1.0, p=0.39$, two-way repeated-measure ANOVA; Bonferroni multiple comparisons: all treatment group comparisons, $p>0.65$ ). However, rats with intra-PVT injection of Flx-TetTox AAV and intraNAc injection of WGA-cre AAV exhibited fewer cocaine infusions over the 5 - $\mathrm{d}$ self-administration period (Figure 1o; treatment group effect: $\mathrm{F}_{3,61}=30.01, p<0.0001$, two-way repeated-measure ANOVA; Bonferroni multiple comparisons: cocaine-ChR2 vs cocaine-TetTox, $p<0.02$; cocaineTetTox $v s$ cocaine-vehicle, $p<0.01)$. After withdrawal from cocaine self-administration, cue-induced cocaine seeking becomes progressively intensified, a phenomenon termed incubation of cue-induced cocaine craving (Grimm et al, 2001). In a 1-h extinction test, sham control rats and rats with intra-PVT injection of Flx-TetTox AAV and intra-NAc injection of WGA-cre AAV exhibited similar increases in cue-induced cocaine seeking from withdrawal day 1 to withdrawal day 45 (Figure 1p; two-way repeated-measure ANOVA; Bonferroni multiple comparisons: vehicle d 1 active $v s$ vehicle $\mathrm{d} 45$ active, $p<0.01$; TetTox $\mathrm{d} 1$ active $v s$ TetTox d 45 active, $p<0.001$; vehicle $45 \mathrm{~d}$ active $v s$ TetTox 45 $\mathrm{d}$ active, $p>0.99$ ), suggesting that, despite the effects on acquisition of cocaine self-administration, disrupting synaptic transmissions in NAc-projecting PVT neurons does not affect incubation of cocaine craving.

\section{Altered Properties of PVT-to-NAc Synapses 1-2 d After Cocaine Self-Administration}

The above results suggest that NAc-projecting PVT neurons are critical for acquiring cocaine self-administration but do not contribute to the withdrawal-associated incubation of cocaine craving. These results raise two questions: (1) are PVT-to-NAc synapses subject to cocaine-induced adaptive changes? and (2) do PVT-to-NAc synapses differ after short- and long-term cocaine withdrawal? To address these questions, we first examined the properties of PVT-to-NAc synapses 1-2 d after cocaine self-administration. Specifically, 3 weeks after intra-PVT injection of channelrhodopsin 2 (ChR2)-expressing $\mathrm{AAV}$, rats underwent the same 5 - $\mathrm{d}$ cocaine self-administration procedure. On withdrawal day 1 or 2, we obtained coronal slices containing the NAc. In NAc shell MSNs, laser stimulation ( $467 \mu \mathrm{m}, 0.1-1 \mathrm{~ms})$ evoked EPSCs, which were presumably from ChR2-expressing PVT-to-NAc synapses. A minimal stimulation assay (Isaac et al, 1995; Liao et al, 1995; Huang et al, 2009) revealed that silent synapse levels were significantly increased within this projection (Figure 2a-c; $t(25)=2.69, p<0.05$, saline $21.27 \pm 8.08 \%$, cocaine $47.03 \pm$ $5.60 \%)$. We also noted that the basal (saline) levels of silent synapses $(\sim 20 \%)$ appear to be higher in this projection than other NAc projections $(<10 \%)$ previously examined in age-matched rats (Lee et al, 2013; Ma et al, 2014). Silent synapses are generally abundant in the developing brain, contributing to active plastic changes at synapses and circuits, but decline to very low levels after development (Durand et al, 1996; Kerchner and Nicoll, 2008). A higher basal level of silent synapses suggests that the PVT-to-NAc projection has greater intrinsic plasticity and is more susceptible to experiencedependent alterations. Given that assessing silent synapses with minimal stimulation involves arbitrary determination of failures $v s$ successes among small synaptic responses, the higher levels of estimated silent synapses may also stem from different criteria of different experimenters. Nonetheless, similar to other NAc afferents, exposure to cocaine generated silent synapses in the PVT-to-NAc projection.

Because only NMDARs are stably functional at silent synapses, generation of silent synapses should lead to decreased ratio of AMPARs over NMDARs when synapses are measured at macroscopic levels. We thus measured the ratio of the amplitudes of AMPAR- and NMDAR-mediated EPSCs at PVT-to-NAc synapses. AMPAR EPSCs were optogenetically elicited (stimulation duration, $0.1-1.5 \mathrm{~ms}$ ) at $-70 \mathrm{mV}$, while NMDAR EPSCs were elicited at $+50 \mathrm{mV}$ with the current amplitude $40 \mathrm{~ms}$ after the current peak defined as the amplitude of NMDAR EPSCs (at this time point, minimal AMPAR-mediated components are active) (Huang et al, 2009). One-to-2 days after cocaine selfadministration, the AMPAR/NMDAR ratio was significantly decreased (Figure $2 \mathrm{~d}$ and e; $t(11)=2.53, p<0.05$, saline $2.21 \pm 0.69$, cocaine $0.58 \pm 0.09$ ), consistent with the above results, indicating that the portion of NMDAR-only synapses is significantly increased.

When synapses are sampled randomly in the NAc shell, cocaine-induced generation of silent synapses is accompanied by an upregulation of synaptic GluN2B-containing NMDARs, and inhibiting GluN2B NMDARs inhibits cocaine-generated silent synapses (Huang et al, 2009). These results together with other results lead to a hypothesis that cocaine-induced generation of silent synapses is a synaptogenesis-like process, involving insertion of GluN2B NMDARs onto new synapses (Dong and Nestler, 2014). In agreement with this hypothesis, the decay kinetics of NMDAR EPSCs at PVT-to-NAc synapses were significantly prolonged 1-2 d after cocaine self-administration, suggesting an increased portion of synaptic GluN2B NMDARs (Figure $2 \mathrm{f}$ and $\mathrm{g} ; t(11)=2.35, p<0.05$, saline $80.76 \pm 14.80$, cocaine $127.02 \pm 13.10)$.

Excitatory synapses on NAc MSNs are enriched in GluA2containing AMPARs, with very low levels of GluA2-lacking, CP-AMPARs in drug-free rats when synapses are sampled randomly (Conrad et al, 2008). However, PVT-to-NAc synapses exhibited a significant basal level of CP-AMPARs. 
Approximately $22 \%$ of AMPAR-mediated EPSCs were inhibited by the CP-AMPAR-selective antagonist Naspm $(150 \mu \mathrm{M})$ (Figure $2 \mathrm{~h}$ and $\mathrm{i} ;(11)=2.96, p<0.05$; saline before
$81.32 \pm 13.23 \mathrm{pA}$ vs saline after $62.43 \pm 9.43 \mathrm{pA})$. Furthermore, the Naspm sensitivity of PVT-to-NAc synapses was not altered $1-2 \mathrm{~d}$ after cocaine self-administration (Figure $2 \mathrm{~h}$

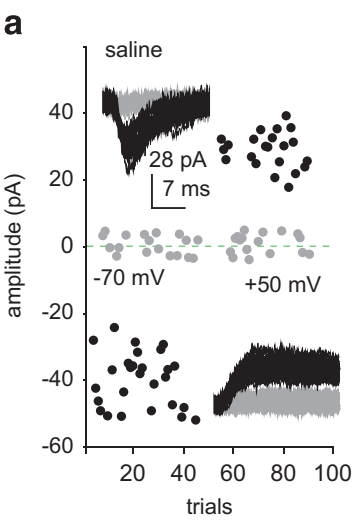

f

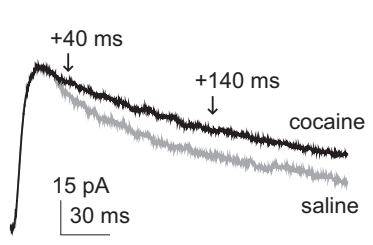

b

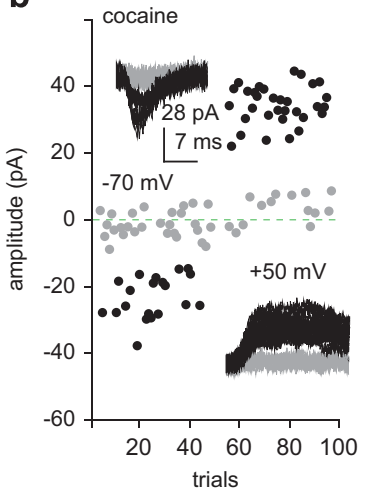

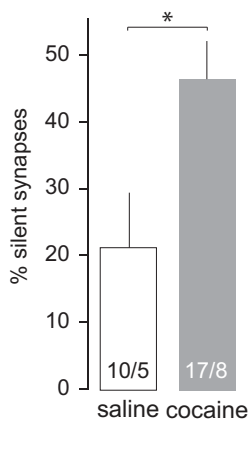

d

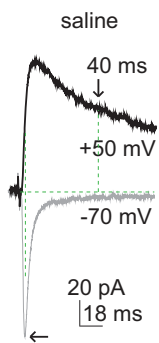

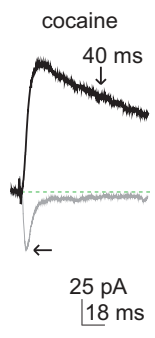

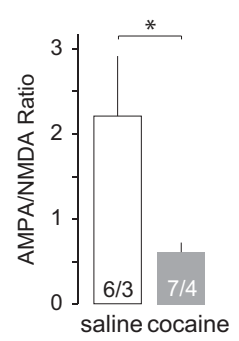

g

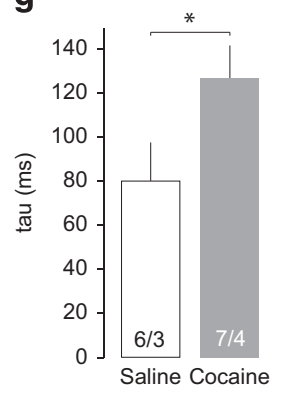

h

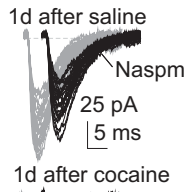

i

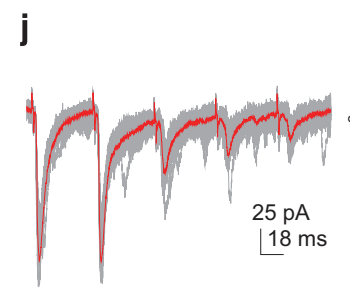

k
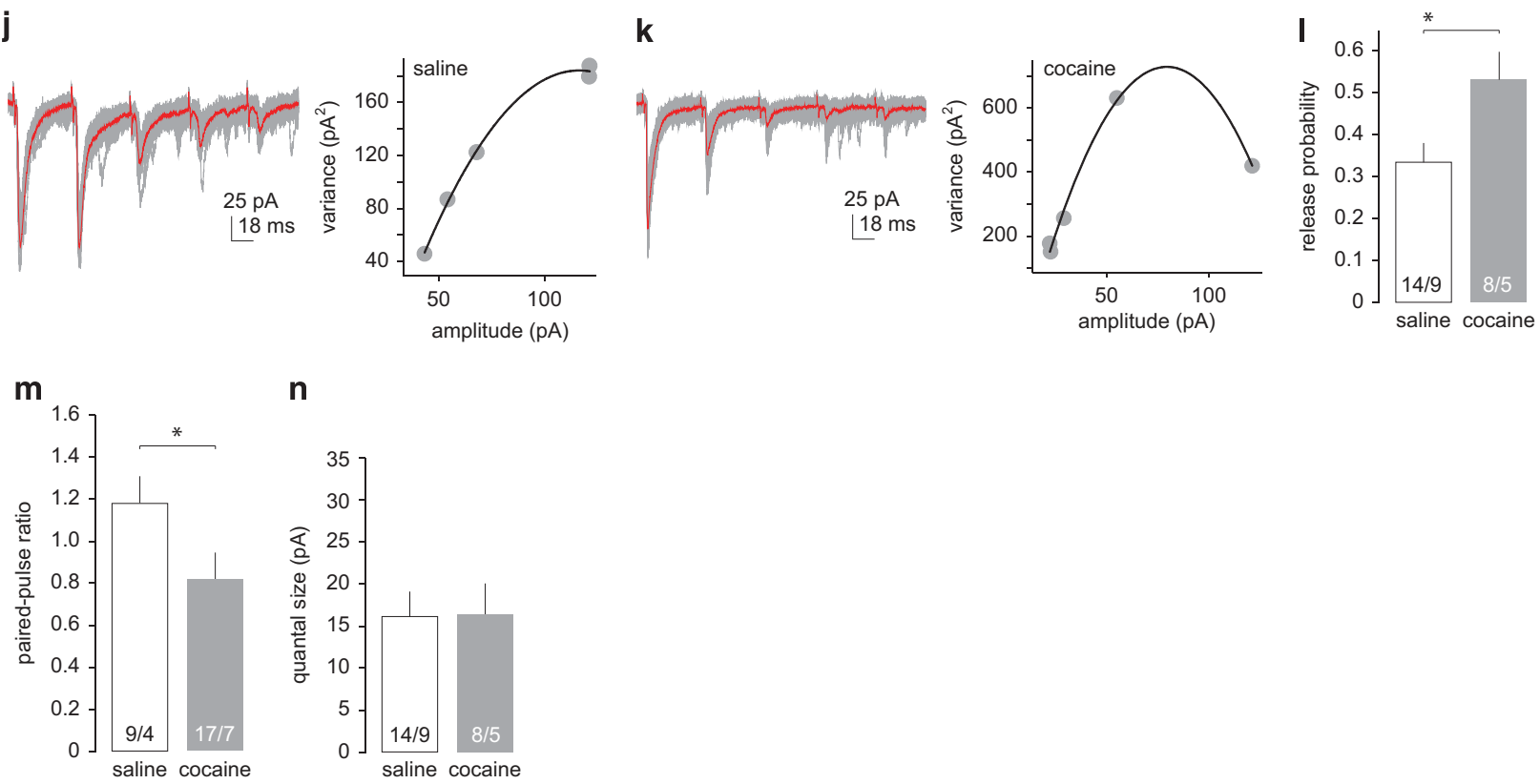

n

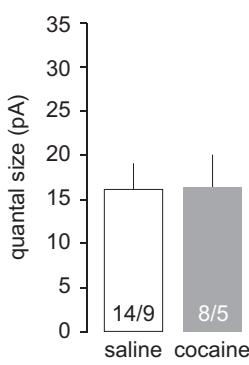

Figure 2 Alterations in PVT-to-NAc synaptic transmission I-2 d after cocaine self-administration. (a, b) Example of minimal stimulation EPSCs and their trials from PVT-to-NAC projections I-2 d after saline (a) and cocaine (b) self-administration. (c) Summary showing increased levels of silent synapses in the PVT-to-NAc projection I-2 d after cocaine self-administration. (d) Example of EPSCs evoked at $-70 \mathrm{mV}$ and $+50 \mathrm{mV}$ from PVT-to-NAc synapses I-2 d after saline or cocaine self-administration. (e) Summary showing decreased AMPAR/NMDAR ratios at PVT-to-NAc synapses. ( $f$ ) Normalized EPSCs from example of MSNs I-2 d after saline or cocaine self-administration. Arrows indicate the range for measuring decay kinetics of NMDAR-mediated EPSCs. (g) Summary showing that the decay kinetics of NMDAR-mediated EPSCs was prolonged I-2 d after cocaine self-administration. (h, i) Example of traces (h) and summary (i) showing similar Naspm-induced inhibition of the peak amplitude of EPSCs at PVT-to-NAc synapses I-2 d after saline or cocaine selfadministration. ( $(j, k)$ Example of EPSCs and their variance-mean hyperbolic fittings at PVT-to-NAc synapses upon 5-pulse $20 \mathrm{~Hz}$ stimulation I-2 d after saline (j) or cocaine ( $k$ ) self-administration. (I) Calculated probability of presynaptic release at PVT-to-NAc synapses I-2 d after saline and cocaine self-administration. (m) Summary showing decreased paired-pulse ratio following saline and cocaine self-administration. (n) Summary showing equivalent quantal sizes following saline and cocaine self-administration. $\mathrm{n} / \mathrm{m}$ (cell/animal) values labeled in key and bars. $* p<0.05$. 
a

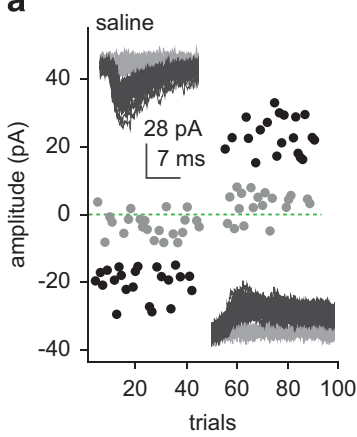

f

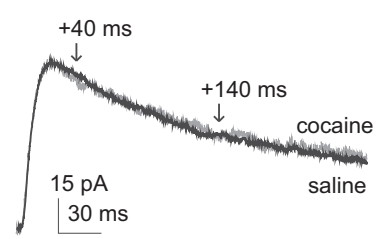

b

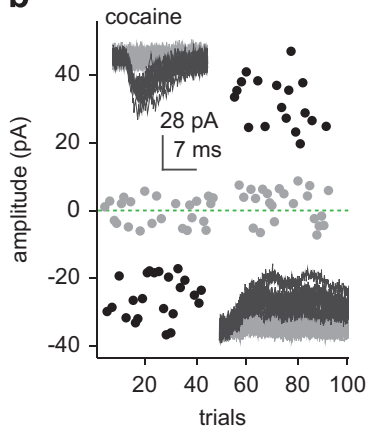

C

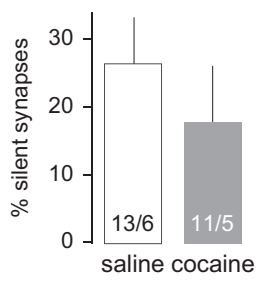

d

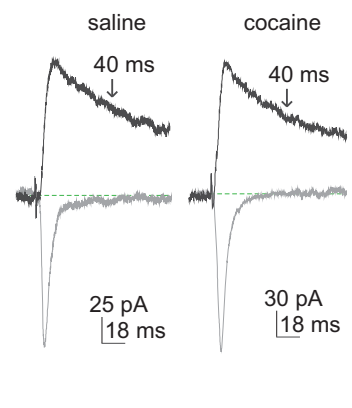

e

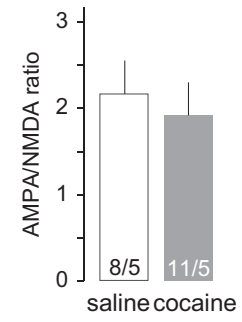

g

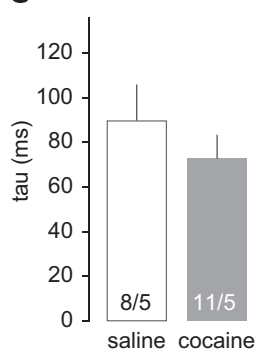

h

45d after saline

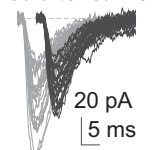

i

j

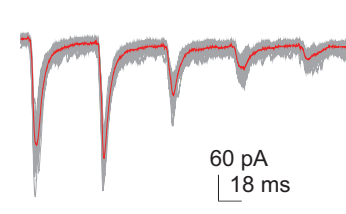

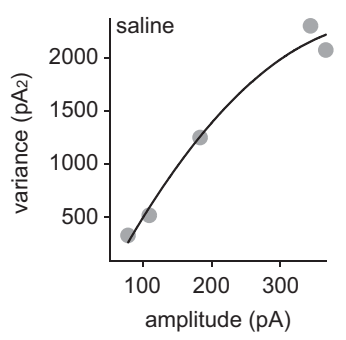

n

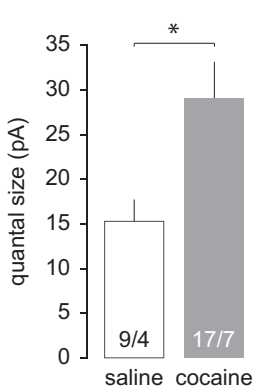

saline cocaine

$45 \mathrm{~d}$ after cocaine

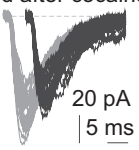

k

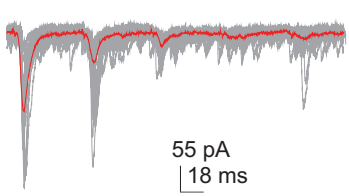

I

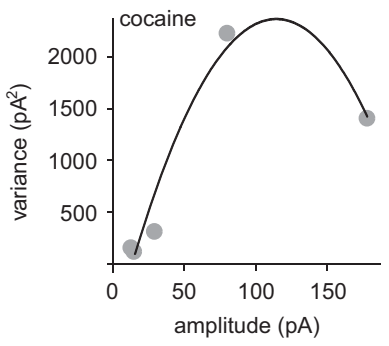

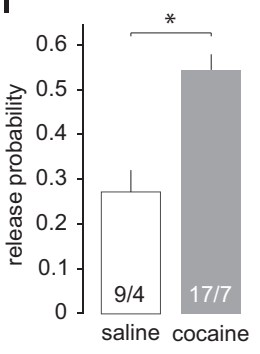

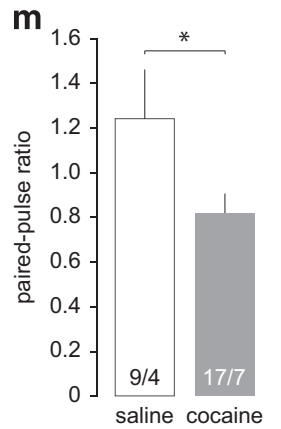

Figure 3 Alterations in PVT-to-NAc synaptic transmission $45 \mathrm{~d}$ after cocaine self-administration. (a, b) Example minimal stimulation EPSCs and their trials from PVT-to-NAc projections $45 \mathrm{~d}$ after saline (a) and cocaine (b) self-administration. (c) Summary showing similar levels of silent synapses in the PVT-to-NAc projection $45 \mathrm{~d}$ after cocaine or saline self-administration. (d) Example of EPSCs evoked at $-70 \mathrm{mV}$ and $+50 \mathrm{mV}$ from PVT-to-NAc synapses $45 \mathrm{~d}$ after saline or cocaine self-administration. (e) Summary showing similar AMPAR/NMDAR ratios at PVT-to-NAc synapses $45 \mathrm{~d}$ after saline or cocaine self-administration. (f) Normalized EPSCs from example of MSNs $45 \mathrm{~d}$ after saline or cocaine self-administration. Arrows indicate the range for measuring decay kinetics of NMDAR-mediated EPSCs. (g) Summary showing similar decay kinetics of NMDAR-mediated EPSCs $45 \mathrm{~d}$ after saline or cocaine self-administration. ( $h$, i) Example of traces (h) and summary (i) showing similar Naspm-induced inhibition of the peak amplitude of EPSC at PVT-to-NAc synapses $45 \mathrm{~d}$ after saline or cocaine self-administration. (j, k) Example of EPSCs and their variance-mean hyperbolic fittings at PVT-to-NAc synapses upon 5-pulse 20 Hz stimulation $45 \mathrm{~d}$ after saline (j) or cocaine ( $\mathrm{k}$ ) self-administration. (I) Calculated probability of presynaptic release at PVT-to-NAc synapses $45 \mathrm{~d}$ after saline and cocaine self-administration. (m) Summary showing decreased paired-pulse ratio following cocaine self-administration. (n) Summary showing increased quantal size following $45 \mathrm{~d}$ withdrawal from cocaine self-administration. $\mathrm{n} / \mathrm{m}$ (cell/animal) values labeled in key and bars. *p $<0.05$.

and i; $t(4)=3.56, p<0.05$, cocaine before $82.60 \pm 14.99 \mathrm{pA} v s$ cocaine after $62.13 \pm 9.28 \mathrm{pA} ;(15)=0.60, p=0.56$, saline after $0.79 \pm 0.05 v s$ cocaine after $0.74 \pm 0.02$ ).

To detect potential presynaptic alterations at this withdrawal time point, we used MPFA (Silver, 2003; Huang et al, 2011; Suska et al, 2013). This involves evoking five consecutive EPSCs at $20 \mathrm{~Hz}$ from PVT-to-NAc synapses, causing each EPSC to evoke at a relatively stable microenvironment for a specific release probability $(\mathrm{Pr})(\mathrm{eg}$, due to different presynaptic calcium concentrations; Figure $2 \mathrm{j}$ and $\mathrm{k}$ ). 
Among 50 trials, the mean amplitudes and variances of each of the five EPSCs were plotted and a parabolic curve was fit (Figure $2 \mathrm{j}$ and $\mathrm{k}$ ). Three presynaptic parameters, the $\operatorname{Pr}$, the quantal size $(Q)$, and the release sites $(N)$ can be derived from the fitted curve (Silver, 2003; also see Materials and Methods section). The MPFA analysis revealed that the $\mathrm{Pr}$ at PVT-to-NAc synapses was significantly increased 1-2 d after cocaine self-administration (Figure 2l; $t(20)=2.46$, $p<0.05$, saline $0.33 \pm 0.04$, cocaine $0.53 \pm 0.07$ ). Additionally, cocaine self-administration led to a decrease in the pairedpulse ratio (PPR, second peak/first peak) of EPSCs (Figure $2 \mathrm{~m} ; t(20)=2.15, p<0.05$; saline $1.19 \pm 0.10$, cocaine $0.81 \pm 0.13$ ), further supporting the observation that presynaptic release probability is higher after cocaine selfadministration. No change in the $Q$ (Figure $2 \mathrm{n} ; t(20)=0.04$, $P=0.97$, saline $16.49 \pm 2.38$, cocaine $16.66 \pm 3.41)$ was detected 1-2 d after cocaine self-administration.

Collectively, 1-2 d after cocaine self-administration, both presynaptic and postsynaptic properties of PVT-to-NAc synapses were substantially altered.

\section{Altered Properties of PVT-to-NAc Synapses 45 d After Cocaine Self-Administration}

After observing substantial differences at PVT-to-NAc synapses 1-2 d after cocaine self-administration, we sought to determine the longevity and the progression of these changes by focusing on a more prolonged withdrawal time point. After 45-d withdrawal from 5-d cocaine self-administration, the percentage of silent synapses within the PVT-to-NAc projection returned to the basal level (Figure $3 a-c ; t(22)=0.77, p=0.45$, saline $26.23 \pm 6.79 \%$, cocaine $18.48 \pm 7.55)$, accompanied by a return of the AMPAR/NMDAR ratio back to basal levels (Figure $3 \mathrm{~d}$ and e; $t(17)=0.52, p=0.61$, saline $2.16 \pm 0.35$, cocaine $1.88 \pm$ $0.38)$. The disappearance of cocaine-generated silent synapses is also accompanied by a return of the decay kinetics of NMDAR-mediated EPSCs back to the basal levels (Figure $3 \mathrm{f}$ and $g ; t(17)=1.01, p=0.21$, saline $90.92 \pm 16.92$, cocaine $73.99 \pm 8.93$ ), suggesting a switch from GluN2B- to GluN2Acontaining NMDARs during the period between withdrawal $\mathrm{d} 1$ and $\mathrm{d}$ 45. In basolateral amygdala and infralimbic prefrontal cortex projections to the NAc, unsilencing of cocaine-generated silent synapses, tested $45 \mathrm{~d}$ after cocaine self-administration, is partially mediated by synaptic insertion of CP-AMPARs. However, in the prelimbic prefrontal cortex to NAc projection, unsilencing of cocaine-generated silent synapses appears to be mediated by insertion of 'normal' GluA2-containing-AMPARs (Lee et al, 2013; $\mathrm{Ma}$ et al, 2014). In the PVT-to-NAc projection, Naspmsensitivity of EPSCs was similar in saline- and cocaineexposed rats $45 \mathrm{~d}$ after self-administration (Figure $3 \mathrm{~h}$ and $\mathrm{i}$; $t(19)=4.08, p<0.01$, saline before $88.40 \pm 19.00 \mathrm{pA} v s$ saline after $65.44 \pm 14.38 \mathrm{pA} ; t(11)=3.94, p<0.01$, cocaine before $76.37 \pm 16.49 \mathrm{pA} v s$ cocaine after $61.94 \pm 14.83 \mathrm{pA}$; $t(30)=0.91, p=0.37$, saline after $0.73 \pm 0.03$ vs cocaine after $0.79 \pm 0.05)$, suggesting that CP-AMPARs are not trafficked to synapses within this pathway after longer-term cocaine withdrawal.

On the other hand, the increased Pr observed after 1-2 d cocaine withdrawal persisted on withdrawal d 45 (Figure $3 \mathrm{j}-1$; $t(24)=4.37, p<0.01$, saline $0.28 \pm 0.04$, cocaine $0.55 \pm 0.4$ )
In agreement, the decrease in PPR after cocaine self-administration also remained (Figure $3 \mathrm{~m} ; t(24)=2.25, p<0.05$, saline $1.27 \pm 0.21$; cocaine $0.83 \pm 0.09$ ). Furthermore, a significant increase in the $Q$ was detected $45 \mathrm{~d}$ after cocaine self-administration (Figure $3 n ; t(24)=2.36, p<0.05$, saline $15.40 \pm 2.31$; cocaine $29.20 \pm 3.89$ ), suggesting that presynaptic release may not only happen more frequently but may also elicit a greater postsynaptic response owing to increases in the levels of transmitter release. Together, these results reveal a persistent increase in presynaptic release and postsynaptic responsiveness following cocaine self-administration and suggest a shifting landscape of synaptic properties within the PVT-to-NAc pathway during withdrawal from cocaine exposure.

\section{DISCUSSION}

Glutamatergic projections to the NAc have a critical role in acquiring and maintaining addictive behaviors. A major source of glutamatergic projection to the NAc is the PVT (Berendse and Groenewegen, 1990; O'Donnell et al, 1997; Van der Werf et al, 2002; Smith et al, 2004; Vertes and Hoover, 2008). Our current results reveal that synaptic transmission in PVT neurons projecting to the NAc is essential for acquisition of cocaine self-administration but not for incubation of cocaine craving after cocaine withdrawal. Furthermore, the PVT-to-NAc projection is subject to silent synapse-based circuitry remodeling. These results demonstrate that the PVT-to-NAc projection is targeted by cocaine experience to reshape NAc circuit and NAc-mediated behaviors.

\section{The PVT-to-NAc Projection}

By simultaneously injecting WGA-cre-expressing AAV into the NAc shell and Flx-TetTox-expressing AAV into the PVT (Xu et al, 2012; Xu and Sudhof, 2013), we disrupted synaptic transmission in PVT neurons that projected to NAc neurons, and this disruption compromised cocaine selfadministration (Figure 1). The rat PVT contains mostly glutamatergic projection neurons (Frassoni et al, 1997). These neurons are activated upon exposure to cocaine or cocaine-associated cues (Brown et al, 1992; Franklin and Druhan, 2000; Matzeu et al, 2015), and disrupting the normal function of these neurons prevents cocaine priminginduced drug reinstatement, sensitization to cocaine, and expression of cocaine-conditioned placed preference (Young and Deutch, 1998; James et al, 2010; Browning et al, 2014). These addiction-related effects are thought to be mediated partially by PVT projections to the limbic system, particularly to the NAc and medial prefrontal cortex (mPFC) (Colavito et al, 2015). Notably, a portion of PVT neurons is highly branched, simultaneously projecting to both the NAc and mPFC (Schenk et al, 1991; Otake and Nakamura, 1998). Thus TetTox expressed in NAc-projecting PVT neurons may also disrupt synaptic transmission in potential co-projections to the mPFC. However, while disrupting the normal operation of the NAc disrupts the acquisition of cocaine self-administration (Roberts et al, 1980), disruption of the mPFC does not (Weissenborn et al, 1997), suggesting that the PVT-to-NAc projection likely has a critical role in cocaine-induced conditioning responses. That being said, 
the roles of other PVT projections in relation to cocaine self-administration remain to be examined in a thorough manner.

\section{Mechanisms Underlying Generation and Maturation of Silent Synapses}

In theory, silent synapses can be generated either by delivering NMDARs to new synaptic locations through a synaptogenesis-like process or internalization/lateralization of AMPARs from preexisting synapses through a synapseweakening process. By randomly sampling NAc synapses without distinguishing their projection origins, our previous studies show that repeated non-contingent exposure to cocaine generates silent synapses in the NAc through a process that is likely mediated by synaptic insertion of new GluN2B-containing NMDARs (Huang et al, 2009; Brown et al, 2011; Dong and Nestler, 2014). In certain projections to the NAc, cocaine-generated silent synapses 'disappear' after cocaine withdrawal through an unsilencing process involving recruitment of AMPARs (Lee et al, 2013; Ma et al, 2014). Thus cocaine-generated silent synapses do not disappear: they are simply no longer distinguishable via minimal stimulation assay because they are no longer silent. Cocainegenerated silent synapses within the PVT-to-NAc projection also demonstrated an increased weight of synaptic GluN2B NMDARs and a decrease in AMPAR/NMDAR ratio (Figure 2), suggesting similar generation and unsilencing mechanisms.

Although it is generally thought that nascent silent synapses are generated as NMDAR-only synapses, synaptic trafficking of AMPARs is also detected during synaptogenesis (Sabo and McAllister, 2003). Furthermore, overexpression of GluA2 subunits increases dendritic spines (Passafaro et al, 2003), indicating that AMPARs have a critical role in synaptogenesis. Moreover, in young hippocampal slices, a set of excitatory synapses that are originally detected as AMPAR-present synapses become NMDAR-only synapses after a few trials of weak activations (Xiao et al, 2004). These and other results lead to the hypothesis that AMPARs are present but are highly labile at nascent synapses and that they become AMPAR-silent synapses upon modest activity (Groc et al, 2006). In line with this scenario, it is possible that both AMPARs and NMDARs are inserted during the initial phase of cocaine-induced generation of silent synapses, while AMPARs are internalized or destabilized soon after.

After prolonged withdrawal $(\sim 45 \mathrm{~d})$ from cocaine selfadministration, cocaine-generated silent synapses become unsilenced by recruiting or stabilizing CP-AMPARs within the infralimbic prefrontal cortex to the NAc projection and within the basolateral amygdala to the NAc projection, and synaptic insertion of CP-AMPARs within these two projections is accompanied by an increased sensitivity to CP-AMPAR-selective antagonist Naspm (Lee et al, 2013; $\mathrm{Ma}$ et al, 2014). However, insertion of CP-AMPARs is not the only route for cocaine-generated silent synapses to become unsilenced; insertion of non-CP-AMPARs potentially mediates the unsilencing of cocaine-generated silent synapses within the prelimbic prefrontal cortex to NAc core projection ( $\mathrm{Ma}$ et al, 2014). Within the PVT-to-NAc projection, the basal level of CP-AMPARs was relatively high, and the levels of synaptic CP-AMPARs were not affected by cocaine exposure and subsequent withdrawal experience, suggesting that maturation of silent synapses within this projection is also mediated by insertion of nonCP-AMPARs (Figures 2 and 3). It has been shown that, after cocaine withdrawal, the level of tonic activity of mGluR1signaling regulates synaptic levels of CP-AMPARs within the NAc (Loweth et al, 2014), whereas synaptic trafficking of non-CP-AMPARs involves NMDARs (Ma et al, 2014). Thus, within the same NAc MSNs, different intracellular signaling pathways are mobilized to regulate maturation of different sets of silent synapses, and our results indicate that cocainegenerated silent synapses within the PVT-to-NAc pathway may recruit non-CP-AMPARs during maturation.

Such highly organized, pathway-specific allocations of intracellular signaling are not only likely to be achieved by postsynaptic MSNs alone but may also be dictated by presynaptic signals. As demonstrated in the present study, the basal presynaptic release probability of PVT-to-NAc synapses was relatively low (Figures 2 and 3) compared with other NAc afferents (Huang et al, 2011; Suska et al, 2013) but was substantially increased after exposure to cocaine (Figures 2 and 3). It is reasonable to speculate that this and other presynaptic properties differentiate distinct projections and dictate unsilencing of cocaine-generated silent synapses after drug withdrawal.

\section{Circuitry Consequences}

The release probability of PVT-to-NAc synapses was persistently increased after cocaine self-administration (Figures 2 and 3 ). If cocaine-induced generation of silent synapses and the subsequent unsilencing of these synapses are indeed a synaptogensis process, this leads to a quantitative increase in the number of synapses, thus strengthening PVT to NAc transmission. The PVT is often regarded as an 'interface' that receives arousal-provoking stimuli signals, including visceral, reward, circadian, and sensory signals, and sends output signals to the NAc that regulate sensorimotor responses and motivated behaviors (Kelley et al, 2005; Parsons et al, 2007; Colavito et al, 2015). An overall strengthening of the PVT-to-NAc projection may thus increase and bias the responsiveness of the NAc to corresponding internal and external stimuli, contributing to the sensitized state of the animal after drug withdrawal.

Strengthened synaptic transmission has been detected in multiple limbic projections to the NAc after withdrawal from cocaine self-administration, and the behavioral roles of these projection-specific adaptations has started to be explored (Britt et al, 2012; Lee et al, 2013; Suska et al, 2013; Ma et al, 2014; MacAskill et al, 2014; Pascoli et al, 2014). The present study reveals that NAc afferents from nontraditional limbic regions are also targeted by cocaine experience. These findings further extend our knowledge about the complex impact of cocaine experience on NAc excitatory synapses.

\section{FUNDING AND DISCLOSURE}

Research presented in the manuscript was supported by NIH MH101147 (to YHH), DA035805 (to YHH), DA023206 (to YD), and DA034856 (to YD). Cocaine was provided by the NIH NIDA drug supply program. The authors declare no conflict of interest. 


\section{ACKNOWLEDGMENTS}

We thank KC Chua for technical assistance and Dr Wei Xu and Dr Thomas Sudhof for TetTox constructs.

\section{REFERENCES}

Auer S, Sturzebecher AS, Juttner R, Santos-Torres J, Hanack C, Frahm S et al (2010). Silencing neurotransmission with membrane-tethered toxins. Nat Methods 7: 229-236.

Berendse HW, Groenewegen HJ (1990). Organization of the thalamostriatal projections in the rat, with special emphasis on the ventral striatum. J Comp Neurol 299: 187-228.

Braz JM, Rico B, Basbaum AI (2002). Transneuronal tracing of diverse CNS circuits by Cre-mediated induction of wheat germ agglutinin in transgenic mice. Proc Natl Acad Sci USA 99: 15148-15153.

Britt JP, Benaliouad F, McDevitt RA, Stuber GD, Wise RA, Bonci A (2012). Synaptic and behavioral profile of multiple glutamatergic inputs to the nucleus accumbens. Neuron 76: 790-803.

Brown EE, Robertson GS, Fibiger HC (1992). Evidence for conditional neuronal activation following exposure to a cocainepaired environment: role of forebrain limbic structures. J Neurosci 12: $4112-4121$.

Brown TE, Lee BR, Mu P, Ferguson D, Dietz D, Ohnishi YN et al (2011). A silent synapse-based mechanism for cocaine-induced locomotor sensitization. J Neurosci 31: 8163-8174.

Browning JR, Jansen HT, Sorg BA (2014). Inactivation of the paraventricular thalamus abolishes the expression of cocaine conditioned place preference in rats. Drug Alcohol Depend 134: 387-390.

Christoffel DJ, Golden SA, Walsh JJ, Guise KG, Heshmati M, Friedman AK et al (2015). Excitatory transmission at thalamostriatal synapses mediates susceptibility to social stress. Nat Neurosci 18: 962-964.

Colavito V, Tesoriero C, Wirtu AT, Grassi-Zucconi G, Bentivoglio M (2015). Limbic thalamus and state-dependent behavior: the paraventricular nucleus of the thalamic midline as a node in circadian timing and sleep/wake-regulatory networks. Neurosci Biobehav Rev 54: 3-17.

Conrad KL, Tseng KY, Uejima JL, Reimers JM, Heng LJ, Shaham Y et al (2008). Formation of accumbens GluR2-lacking AMPA receptors mediates incubation of cocaine craving. Nature 454: $118-121$.

Dong Y, Green T, Saal D, Marie H, Neve R, Nestler EJ et al (2006). CREB modulates excitability of nucleus accumbens neurons. Nat Neurosci 9: 475-477.

Dong Y, Nestler EJ (2014). The neural rejuvenation hypothesis of cocaine addiction. Trends Pharmacol Sci 35: 374-383.

Durand GM, Kovalchuk Y, Konnerth A (1996). Long-term potentiation and functional synapse induction in developing hippocampus. Nature 381: 71-75.

Franklin TR, Druhan JP (2000). Expression of Fos-related antigens in the nucleus accumbens and associated regions following exposure to a cocaine-paired environment. Eur J Neurosci 12: 2097-2106.

Frassoni C, Spreafico R, Bentivoglio M (1997). Glutamate, aspartate and co-localization with calbindin in the medial thalamus. An immunohistochemical study in the rat. Exp Brain Res 115: 95-104.

Grimm JW, Hope BT, Wise RA, Shaham Y (2001). Neuroadaptation. Incubation of cocaine craving after withdrawal. Nature 412: $141-142$.

Groc L, Gustafsson B, Hanse E (2006). AMPA signalling in nascent glutamatergic synapses: there and not there! Trends Neurosci 29: $132-139$.
Huang YH, Ishikawa M, Lee BR, Nakanishi N, Schluter OM, Dong Y (2011). Searching for presynaptic NMDA receptors in the nucleus accumbens. J Neurosci 31: 18453-18463.

Huang YH, Lin Y, Brown TE, Han MH, Saal DB, Neve RL et al (2008). CREB modulates the functional output of nucleus accumbens neurons: a critical role of N-methyl-D-aspartate glutamate receptor (NMDAR) receptors. J Biol Chem 283: 2751-2760.

Huang YH, Lin Y, Mu P, Lee BR, Brown TE, Wayman G et al (2009). In vivo cocaine experience generates silent synapses. Neuron 63: 40-47.

Huang YH, Schluter OM, Dong Y (2013). An unusual suspect in cocaine addiction. Neuron 80: 835-836.

Isaac JT, Nicoll RA, Malenka RC (1995). Evidence for silent synapses: implications for the expression of LTP. Neuron 15: 427-434.

James MH, Charnley JL, Jones E, Levi EM, Yeoh JW, Flynn JR et al (2010). Cocaine- and amphetamine-regulated transcript (CART) signaling within the paraventricular thalamus modulates cocaineseeking behaviour. PLoS One 5: e12980.

Kelley AE, Baldo BA, Pratt WE, Will MJ (2005). Corticostriatalhypothalamic circuitry and food motivation: integration of energy, action and reward. Physiol Behav 86: 773-795.

Kerchner GA, Nicoll RA (2008). Silent synapses and the emergence of a postsynaptic mechanism for LTP. Nat Rev Neurosci 9: 813-825.

Klugmann M, Symes CW, Leichtlein CB, Klaussner BK, Dunning J, Fong D et al (2005). AAV-mediated hippocampal expression of short and long Homer 1 proteins differentially affect cognition and seizure activity in adult rats. Mol Cell Neurosci 28: 347-360.

Lee BR, Dong Y (2011). Cocaine-induced metaplasticity in the nucleus accumbens: silent synapse and beyond. Neuropharmacology 61: 1060-1069.

Lee BR, Ma YY, Huang YH, Wang X, Otaka M, Ishikawa M et al (2013). Maturation of silent synapses in amygdala-accumbens projection contributes to incubation of cocaine craving. Nat Neurosci 16: 1644-1651.

Liao D, Hessler NA, Malinow R (1995). Activation of postsynaptically silent synapses during pairing-induced LTP in CA1 region of hippocampal slice. Nature 375: 400-404.

Loweth JA, Scheyer AF, Milovanovic M, LaCrosse AL, Flores-Barrera E, Werner CT et al (2014). Synaptic depression via mGluR1 positive allosteric modulation suppresses cueinduced cocaine craving. Nat Neurosci 17: 73-80.

Ma YY, Lee BR, Wang X, Guo C, Liu L, Cui R et al (2014). Bidirectional modulation of incubation of cocaine craving by silent synapse-based remodeling of prefrontal cortex to accumbens projections. Neuron 83: 1453-1467.

MacAskill AF, Cassel JM, Carter AG (2014). Cocaine exposure reorganizes cell type- and input-specific connectivity in the nucleus accumbens. Nat Neurosci 17: 1198-1207.

Mattis J, Tye KM, Ferenczi EA, Ramakrishnan C, O'Shea DJ, Prakash R et al (2012). Principles for applying optogenetic tools derived from direct comparative analysis of microbial opsins. Nat Methods 9: 159-172.

Matzeu A, Cauvi G, Kerr TM, Weiss F, Martin-Fardon R (2015). The paraventricular nucleus of the thalamus is differentially recruited by stimuli conditioned to the availability of cocaine versus palatable food. Addict Biol (e-pub ahead of print).

Matzeu A, Zamora-Martinez ER, Martin-Fardon R (2014). The paraventricular nucleus of the thalamus is recruited by both natural rewards and drugs of abuse: recent evidence of a pivotal role for orexin/hypocretin signaling in this thalamic nucleus in drug-seeking behavior. Front Behav Neurosci 8: 117.

Mu P, Moyer JT, Ishikawa M, Zhang Y, Panksepp J, Sorg BA et al (2010). Exposure to cocaine dynamically regulates the intrinsic membrane excitability of nucleus accumbens neurons. J Neurosci 30: 3689-3699. 
O'Donnell P, Lavin A, Enquist LW, Grace AA, Card JP (1997). Interconnected parallel circuits between rat nucleus accumbens and thalamus revealed by retrograde transynaptic transport of pseudorabies virus. J Neurosci 17: 2143-2167.

Otake K, Nakamura Y (1998). Single midline thalamic neurons projecting to both the ventral striatum and the prefrontal cortex in the rat. Neuroscience 86: 635-649.

Parsons MP, Li S, Kirouac GJ (2007). Functional and anatomical connection between the paraventricular nucleus of the thalamus and dopamine fibers of the nucleus accumbens. J Comp Neurol 500: 1050-1063.

Pascoli V, Terrier J, Espallergues J, Valjent E, O'Connor EC, Luscher C (2014). Contrasting forms of cocaine-evoked plasticity control components of relapse. Nature 509: 459-464.

Passafaro M, Nakagawa T, Sala C, Sheng M (2003). Induction of dendritic spines by an extracellular domain of AMPA receptor subunit GluR2. Nature 424: 677-681.

Pilpel N, Landeck N, Klugmann M, Seeburg PH, Schwarz MK (2009). Rapid, reproducible transduction of select forebrain regions by targeted recombinant virus injection into the neonatal mouse brain. J Neurosci Methods 182: 55-63.

Pinto A, Jankowski M, Sesack SR (2003). Projections from the paraventricular nucleus of the thalamus to the rat prefrontal cortex and nucleus accumbens shell: ultrastructural characteristics and spatial relationships with dopamine afferents. J Comp Neurol 459: $142-155$.

Roberts DC, Koob GF, Klonoff P, Fibiger HC (1980). Extinction and recovery of cocaine self-administration following 6hydroxydopamine lesions of the nucleus accumbens. Pharmacol Biochem Behav 12: 781-787.

Robinson TE, Kolb B (2004). Structural plasticity associated with exposure to drugs of abuse. Neuropharmacology 47(Suppl 1): 33-46.

Sabo SL, McAllister AK (2003). Mobility and cycling of synaptic protein-containing vesicles in axonal growth cone filopodia. Nat Neurosci 6: 1264-1269.

Schenk S, Horger BA, Peltier R, Shelton K (1991). Supersensitivity to the reinforcing effects of cocaine following 6-hydroxydopamine lesions to the medial prefrontal cortex in rats. Brain Res 543: 227-235.

Scheuss V, Neher E (2001). Estimating synaptic parameters from mean, variance, and covariance in trains of synaptic responses. Biophys J 81: 1970-1989.
Silver RA (2003). Estimation of nonuniform quantal parameters with multiple-probability fluctuation analysis: theory, application and limitations. J Neurosci Methods 130: 127-141.

Smith Y, Raju DV, Pare JF, Sidibe M (2004). The thalamostriatal system: a highly specific network of the basal ganglia circuitry. Trends Neurosci 27: 520-527.

Suska A, Lee BR, Huang YH, Dong Y, Schluter OM (2013). Selective presynaptic enhancement of the prefrontal cortex to nucleus accumbens pathway by cocaine. Proc Natl Acad Sci USA 110: 713-718.

Van der Werf YD, Witter MP, Groenewegen HJ (2002). The intralaminar and midline nuclei of the thalamus. Anatomical and functional evidence for participation in processes of arousal and awareness. Brain Res Brain Res Rev 39: 107-140.

Vertes RP, Hoover WB (2008). Projections of the paraventricular and paratenial nuclei of the dorsal midline thalamus in the rat. J Comp Neurol 508: 212-237.

Veznedaroglu E, Milner TA (1992). Elimination of artifactual labeling of hippocampal mossy fibers seen following preembedding immunogold-silver technique by pretreatment with zinc chelator. Microsc Res Tech 23: 100-101.

Weissenborn R, Robbins TW, Everitt BJ (1997). Effects of medial prefrontal or anterior cingulate cortex lesions on responding for cocaine under fixed-ratio and second-order schedules of reinforcement in rats. Psychopharmacology 134: 242-257.

Wolf ME (2010). The Bermuda Triangle of cocaine-induced neuroadaptations. Trends Neurosci 33: 391-398.

Xiao MY, Wasling P, Hanse E, Gustafsson B (2004). Creation of AMPA-silent synapses in the neonatal hippocampus. Nat Neurosci 7: 236-243.

Xu W, Morishita W, Buckmaster PS, Pang ZP, Malenka RC, Sudhof TC (2012). Distinct neuronal coding schemes in memory revealed by selective erasure of fast synchronous synaptic transmission. Neuron 73: 990-1001.

Xu W, Sudhof TC (2013). A neural circuit for memory specificity and generalization. Science 339: 1290-1295.

Young CD, Deutch AY (1998). The effects of thalamic paraventricular nucleus lesions on cocaine-induced locomotor activity and sensitization. Pharmacol Biochem Behav 60: 753-758.

Zolotukhin S, Byrne BJ, Mason E, Zolotukhin I, Potter M, Chesnut $\mathrm{K}$ et al (1999). Recombinant adeno-associated virus purification using novel methods improves infectious titer and yield. Gene Therapy 6: 973-985. 